\title{
Rehabilitation of a patient with Screw-Retained Metal-Resin Implant-Tissue Supported Fixed Mandibular Complete Denture: A Hybrid Prosthesis (FP - 3): A Case Report
}

\author{
Dr. Ravi Shankar, Dr. Mahinder Singh Chauhan ${ }^{2}$, Dr. Gaurav Sharma ${ }^{3}$, \\ Dr. Prashant Tyagi ${ }^{4}$ \\ ${ }^{1}$ (P.G Student,Dept. of Prosthodontics, Rama Dental College and Research Centre,Kanpur,India) \\ ${ }_{2}^{2}$ (P.G Student,Dept. of Prosthodontics, Rama Dental College and Research Centre,Kanpur,India) \\ ${ }^{3}$ (P.G Student,Dept. of Oral and Maxillofacial Surgery, Rama Dental College and Research \\ Centre,Kanpur,India) \\ ${ }^{4}$ (Sr.Lecturer, Dept of Periodontics,Shree Bankey Bihari Dental College, Ghaziabad,India)
}

\begin{abstract}
A$ hybrid denture is one that is fabricated over a metal framework and retained by screws threaded into the implants. The anterior part of a mandibular hybrid denture is fixed on implants while the posterior part of the denture is extended and cantilevered from implants. This article presents the fabrication of a mandibular implant retained hybrid prosthesis. A total of four implants were placed in the mandibular arch. Framework was waxed, plastic castable abutments were used, casting was done, denture teeth were waxed to the hybrid framework and a final wax try-in was performed to verify and correct maxillomandibular relations before processing. The prosthesis was inserted after verification of occlusion, retention and to cast recovered and the fit was refined until the framework seated passively on the master cast. The mandibular achieve greater masticatory function and psychological satisfaction than with conventional over-dentures. Producing a passivefitting substructure for a fixed removable screw retained hybrid prosthesis is one of the most technically complex tasks in implant dentistry. The technique presented describes a step by step procedure for achieving a perfectly fitted mandibular hybrid prosthesis.
\end{abstract}

\section{Introduction}

The rehabilitation of the completely edentulous patient is a major responsibility for the prosthodontist. Though, conventional complete dentures provide reliable service, the anatomic limitations, tissue changes underneath the denture and the psychological make-up of the patient contribute to the poor performance of the prosthesis. ${ }^{[1]}$

Mandibular implant-supported hybrid prostheses have been used for edentulous patients who could not adapt to long-term use of conventional complete dentures. ${ }^{[2]}$ Zarb and Symington developed the hybrid prosthesis by attaching denture teeth with heat-polymerized acrylic resin to a cast metal substructure. ${ }^{[3]}$ The anterior part of a mandibular hybrid denture is fixed on implants while the posterior part of the denture is extended and cantilevered from implants.

Dental reconstruction and rehabilitation in edentulous patients can be performed by using screwretained hybrid prosthesis, screw-retained metal ceramic prosthesis and cement-retained metal ceramic prosthesis. Use of screw-retained prosthesis is recommended for patients suffering from weak denture retention because this type of prosthesis can be easily placed and retrieved ${ }^{[4]}$.Apart from the abovementioned advantages, hybrid prostheses can also replace soft tissue defects. However, lack of passive fit in the framework and distortion (which is possible to occur anytime during the fabrication) are major obstacles in the process of prosthesis fabrication ${ }^{[5]}$.

Generally, hybrid prosthesis is the recommended treatment for patients suffering from severe alveolar ridge resorption ${ }^{[6-8]}$.

\section{Case Report}

A 46 year-old female patient came to the Department of Prosthodontics, Rama Dental College, Kanpur for dental reconstruction.

The patient had partially dentulous maxillary arch and completely edentulous mandibular arch. She had lost her teeth due to periodontal disease (Figures 1-2). 

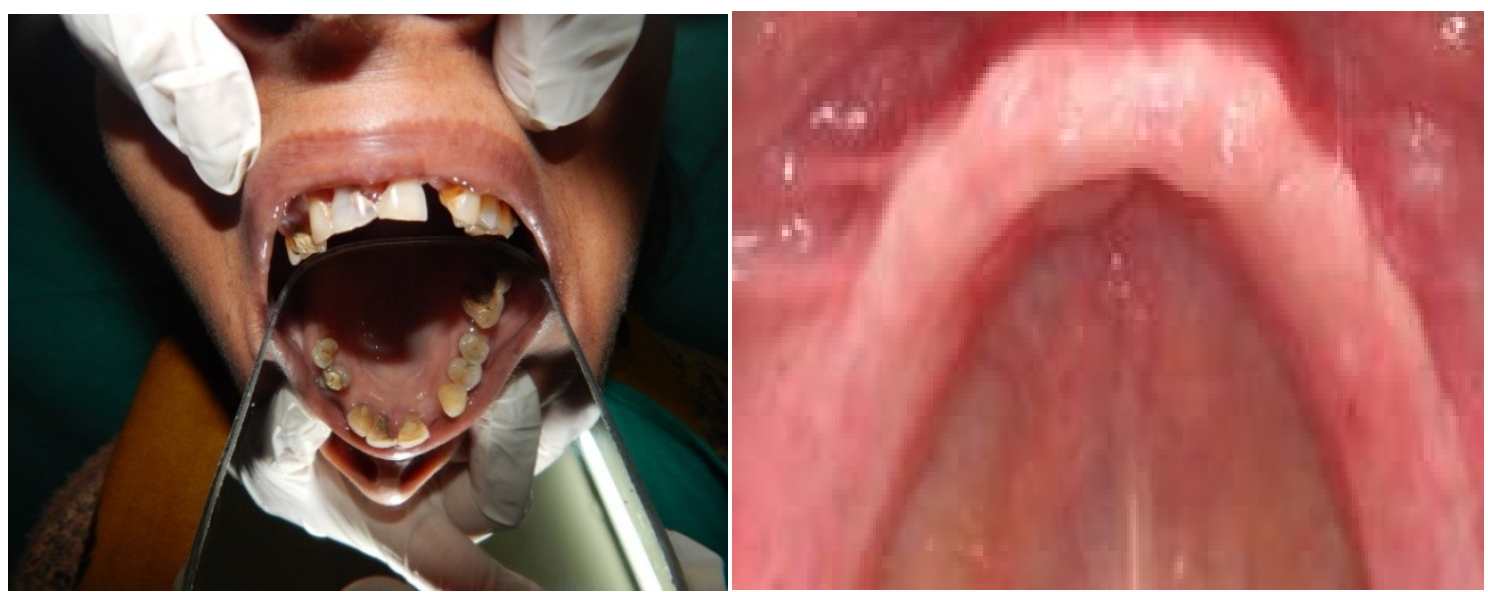

Figure 1 : Pre-Operative Maxillary And Mandibular Arches

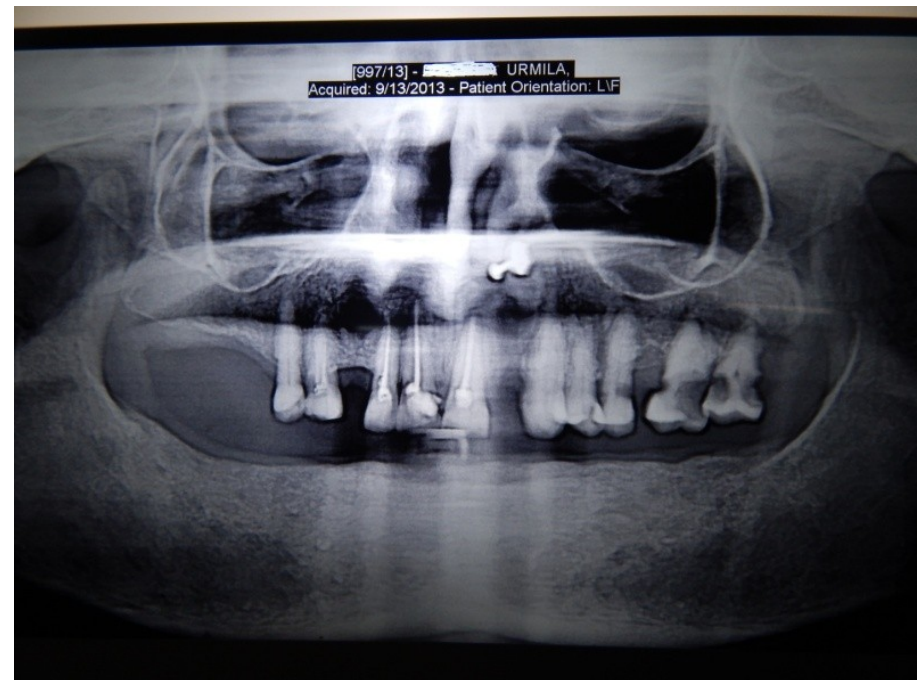

Figure 2: Pre-Operative OPG (Orthopantomograph)

Initially a removable complete denture was fabricated for the mandibular arch. ( Fig. 3).

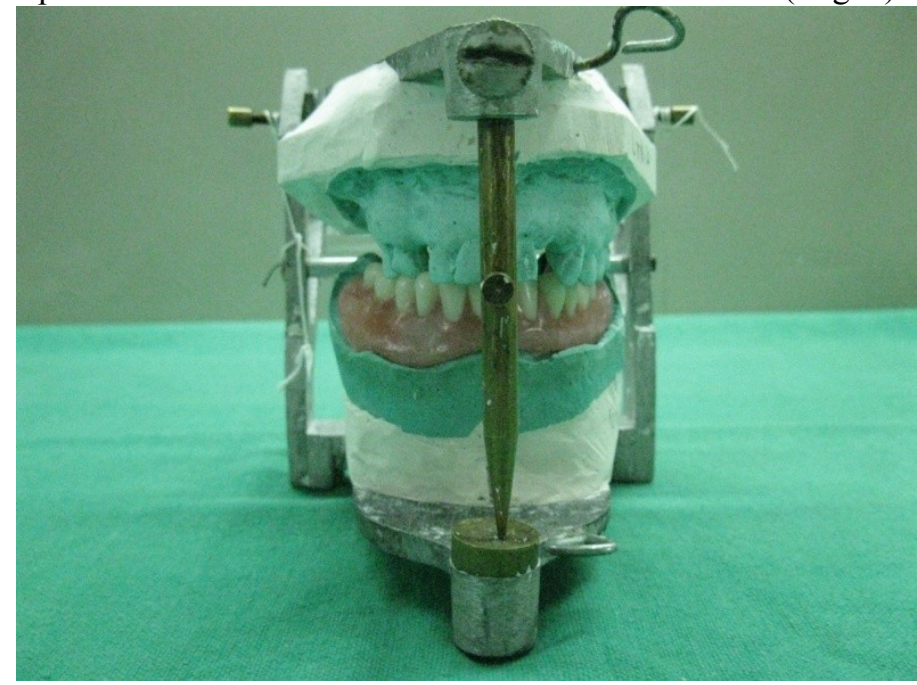

Figure 3 : Removable Mandibular Complete Denture

But the patient's desire was to eliminate a removable prosthesis in the mandible. Therefore fabrication of screw retained implant-tissue supported hybrid prosthesis was planned for the mandibular arch. 
The following clinical and laboratory procedures were performed :

\section{Stage I Implant Surgery :}

A full thickness mucoperiosteal flap was raised in the mandibular arch from distal to mental foramen on one side to mental foramen on the other side. In the right quadrant, implants (Tapered self-thread, ADIN implant system) were placed in the $2^{\text {nd }}$ premolar $(3.5 \mathrm{~mm} \times 11.5 \mathrm{~mm})$ and canine $(3.5 \mathrm{~mm} \times 13 \mathrm{~mm})$ regions. In the left quadrant, implants were placed in $2^{\text {nd }}$ premolar $(3.5 \mathrm{~mm} \times 11.5 \mathrm{~mm})$ and canine $(3.5 \mathrm{~mm} \times 11.5 \mathrm{~mm})$ regions.

A total of four implants were placed in the mandibular arch. The flap was closed with sutures( Fig. 4 ). After 1 week, the sutures were removed.
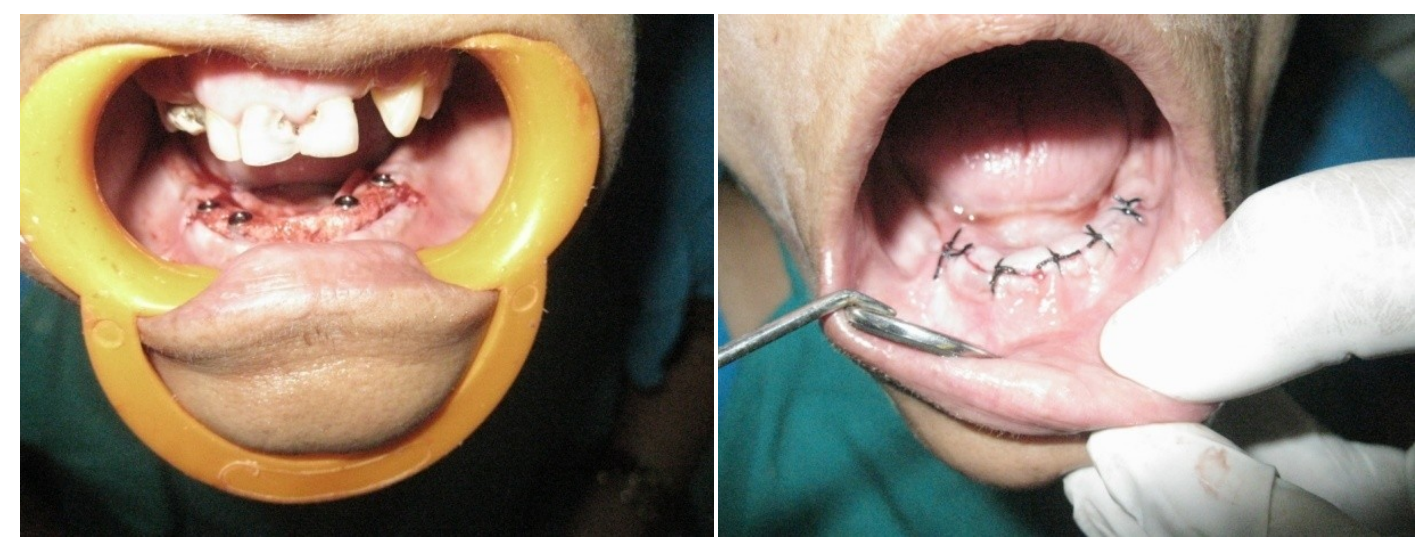

Figure 4 : Implants Placed And Flap Was Closed With Sutures.

\section{Stage 2 : Implant Surgery :}

After a waiting period of 1 month, an OPG (Orthopantomograph) was obtained to evaluate the bone to implant contact percentage ( Figure 5) and later stage II surgery was performed under local anesthesia cover screws were exposed and healing abutments were placed.( Fig. 6 ).
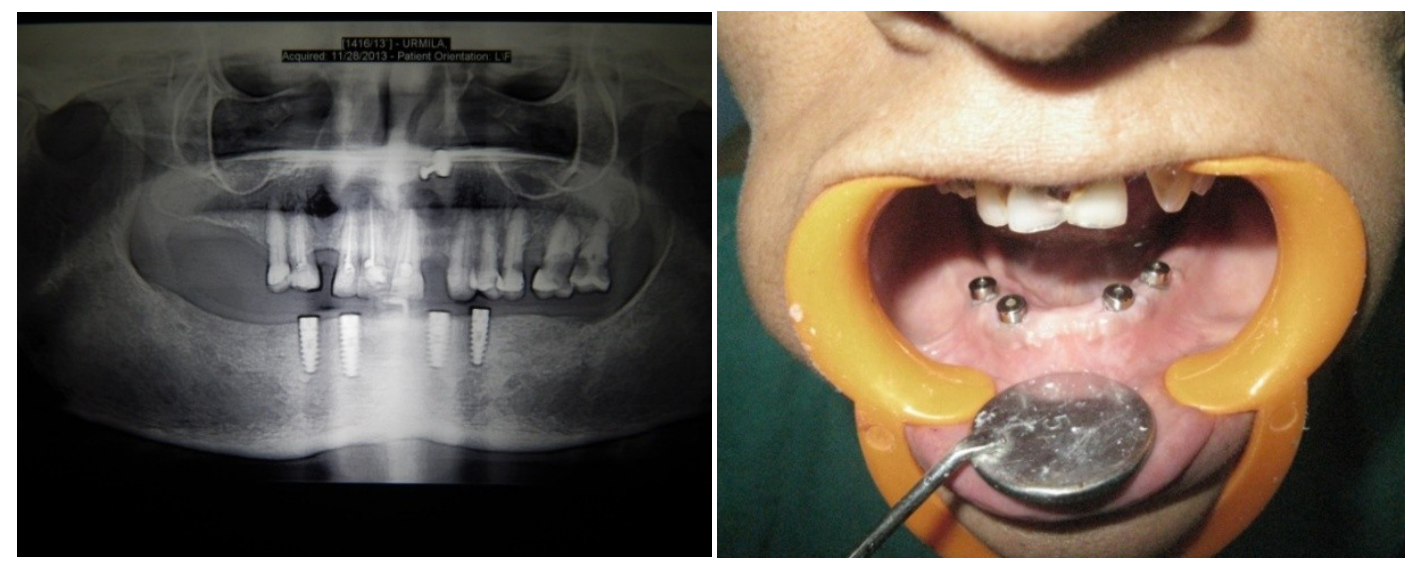

Figure 5 : Post-Operative OPG

Figure 6 : Healing Abutments Were Placed Over Implant Bodies.

\section{Prosthetic Phase :}

Prefabricated removable mandibular complete denture was used as a special tray and it was trimmed in the anterior region so that adequate space can be obtained for the impression material between the tray and implants. ( Fig. 7 ) After 1 week, when the soft tissue has grown around healing abutments, the healing abutments were removed, and impression copings were connected to the implants for the open-tray technique ( Fig. 8 ) 

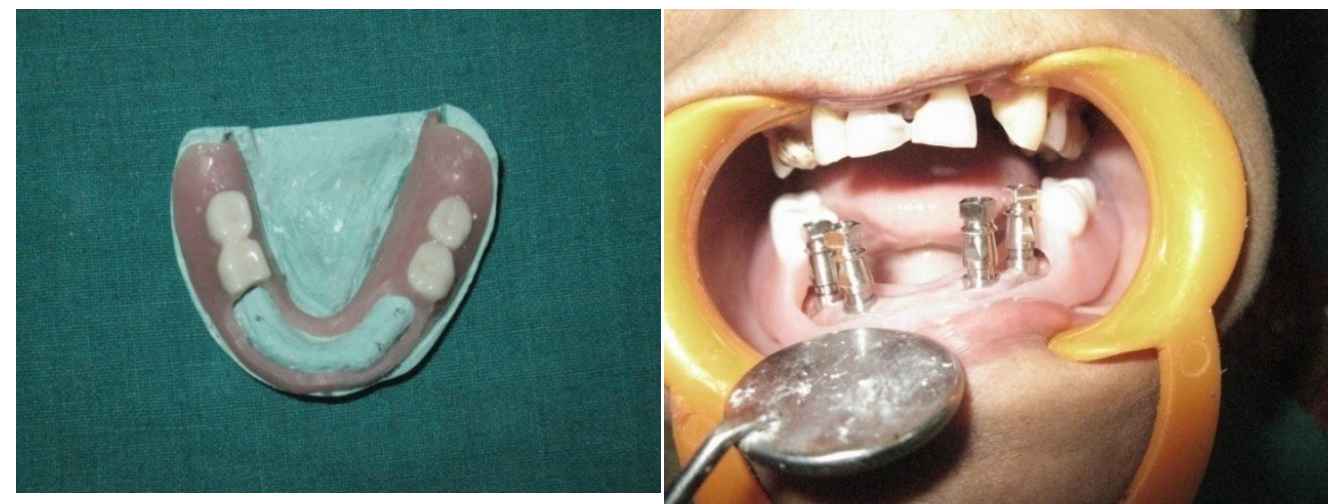

Figure 7 : prefabricated removable complete figure 8 : impression copings were denture was used as a special tray. attached to the implant bodies.

A two-piece implant transfer system was utilized, consisting of square shaped impression copings and long fixation screws allowing precise connection to the implant. The copings were attached to the implants with a Hex Tool. The tray had an open window to allow for the internal screw to be loosened, as the body of the transfer post will remain within the impression. Before making impression, tray adhesive was applied to the open-tray. (Fig. 9 ) The tray was then filled with the addition silicone impression material (Exaflex, vinyl polysiloxane impression material, U.S.A.) and delivered over the impression copings and lower arch. The impression copings were incorporated into the impression. With the tray still in place, the retaining screws were unscrewed and removed. Then tray was removed, capturing the impression copings in the impression material. (Fig. 10 )

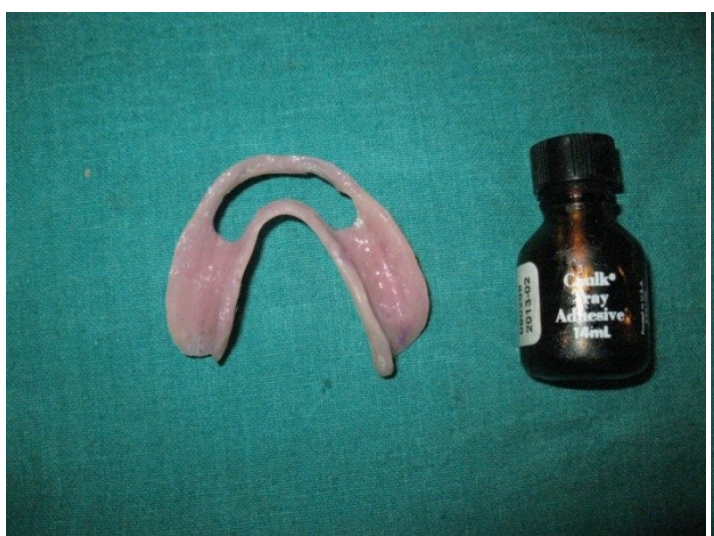

Figure 9: tray adhesive was applied to before making impression

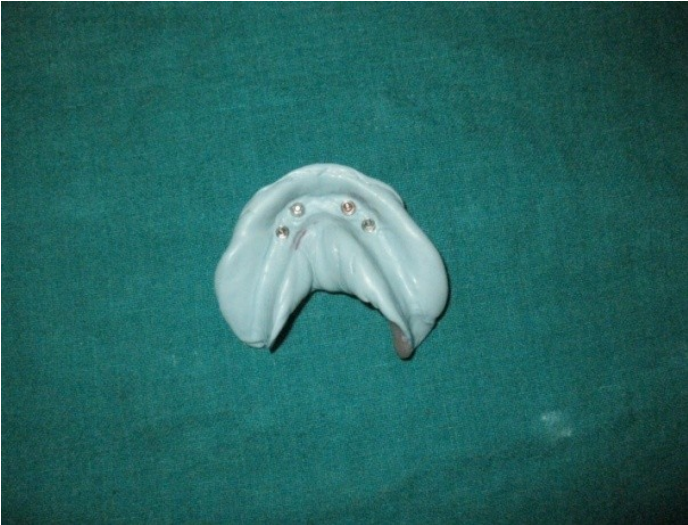

figure 10 : impression copings entrapped special tray into the impression.

After removing the impression tray, implant replicas were connected to the impression copings which were still in place in the impression material. Screw impression copings and replicas together with the Hex Tool. The replicas were held in place to prevent rotation of the impression copings. (Fig. 11) a layer of petroleum jelly was applied over the impression around the implant replicas, after that one thin layer of light body addition silicon impression material (Examix NDS, Hydrophilic Vinyl Polysiloxane Impression Material, Gc America Inc. ) was applied around implant replicas to simulate the soft tissue around them. (Fig. 12 ) The healing abutments were again attached to the implants and patient was sent. 

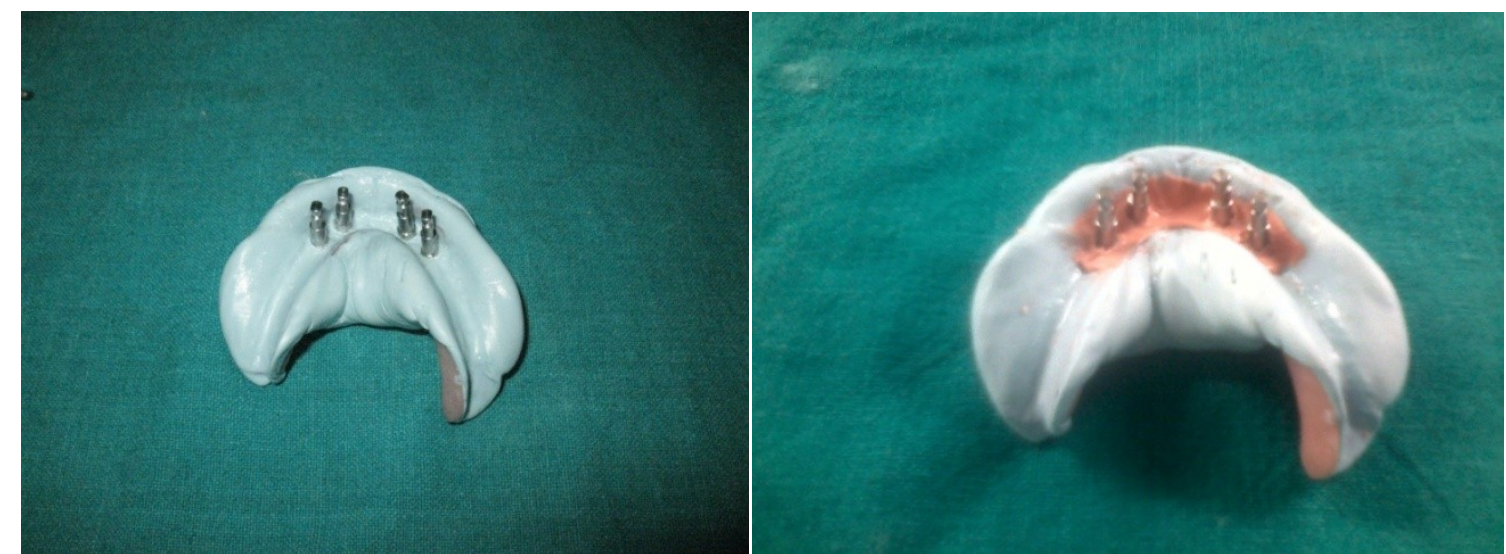

Figure 11: Implant replicas ( analogues ) were the impression copings

Figure 12 : light body impression material is connected to applied around the impression replicas

In the lab, impressions were poured in die stone (Denstone, dental stone plaster, M.P, India) Master casts were recovered. The Implant replicas were embedded inside the master cast. (Fig. 13). Metal abutments were attached to the implant replicas incorporated into the master cast, to get a rough idea of the inter-arch space required for the fabrication of mandibular hybrid prosthesis. Record bases and occlusion rims were fabricated. ( Fig. 14 ) Patient was recalled for recording of maxillomandibular relations and tooth selection. (Fig. 15)

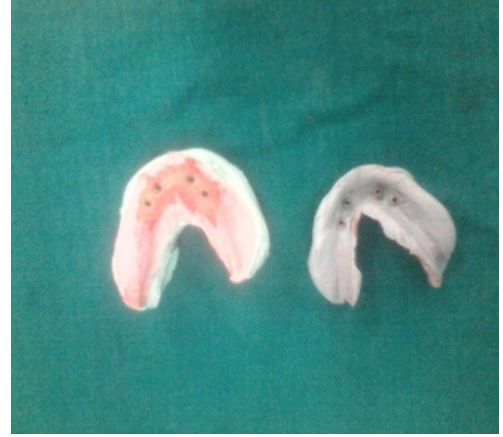

Figure 13 : master cast was Figure 14 : Record bases and occlusion rims were fabricated.
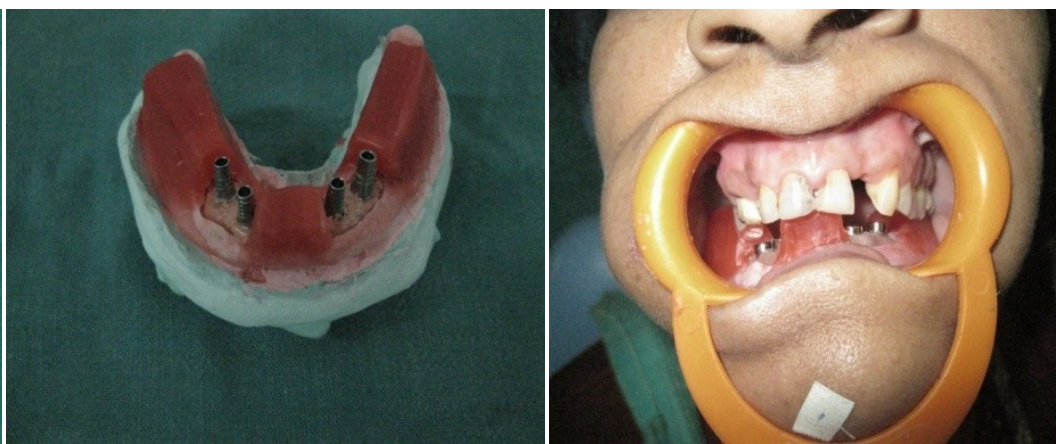

Figure 15 : recording of recovered maxillomandibular relations.

Master casts were then mounted on an articulator. The framework was waxed, cast, recovered, and fitted on the master cast. (Fig. 16-18)

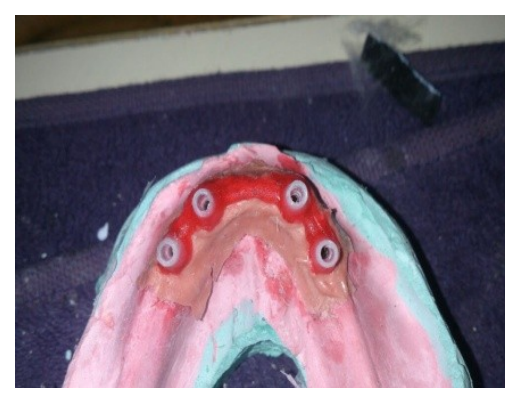

Figure 16 : plastic castable abutments were connected with the implant

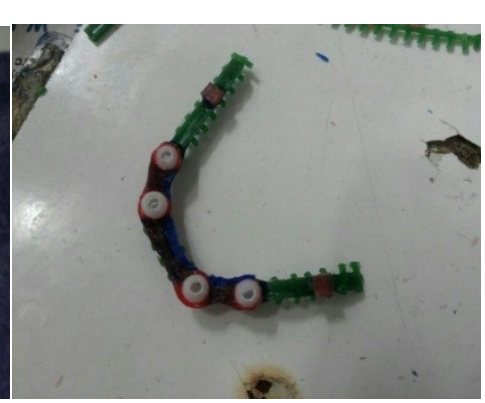

Figure 17 : Was pattern for the metal framework

replicas in the master cast

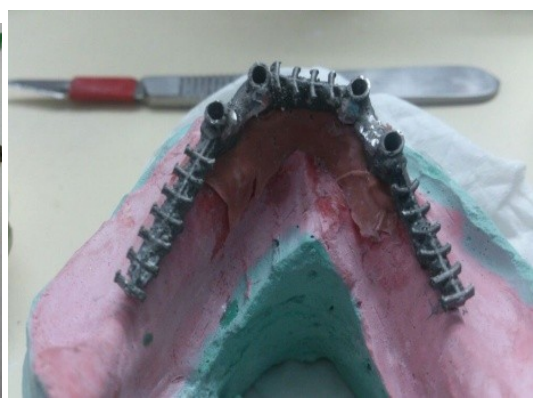

Figure 18 : metal framework was checked on the master cast for passive fitting

The fit was refined until the framework seated passively on the master cast. The mandibular denture teeth were waxed to the hybrid framework, and a final wax try-in was performed to verify and correct maxillomandibular relations. At this appointment, the customized abutments along with the framework were connected to the implants for the final wax try-in. fig (19). 


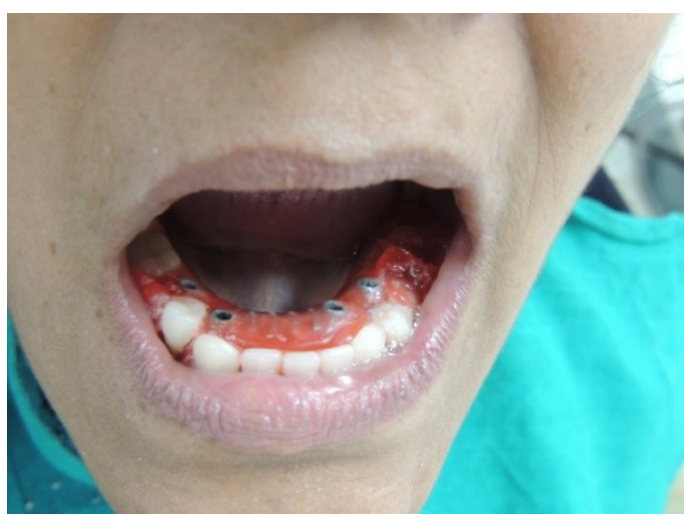

Figure 19 : final wax try-in was performed to verify and correct maxillomandibular relations.

The investing, flasking, and processing procedures for the hybrid prosthesis were then completed. The prosthesis was finished and polished, the hybrid prosthesis was screw retained and composite resin was used to cover screw access hole. Hygiene techniques were reviewed, and patient was scheduled for recall and maintenance. (Fig. 20-21)

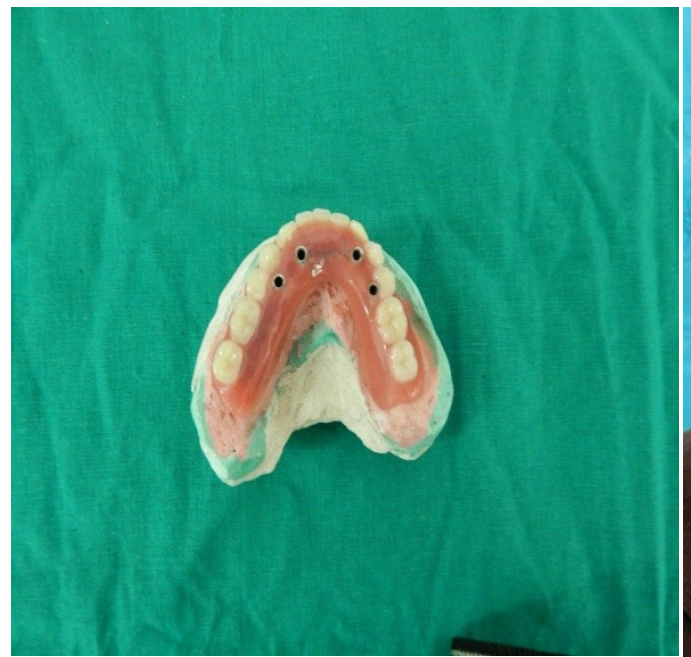

Figure 20 : finished and polished hybrid prosthesis

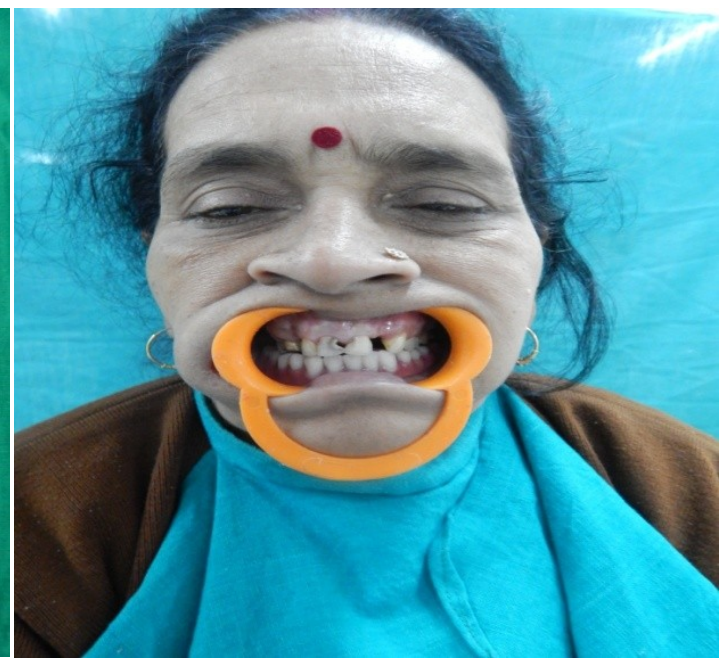

Figure 21 : the hybrid prosthesis was screw retained

\section{Discussion}

There might be occlusal stress on the removable mandibular denture and the underlying edentulous tissue due to forces from teeth and musculature and opposing natural teeth, and the position of the maxillary teeth,which are improperly aligned may also avoid achievement of bilateral balance for stability and lead flexure of the denture bases. The midline fracture in a denture is often a result of flexural fatigue. Though poly Methyl Metha Acrylate denture bases have good mechanical, biological and esthetic properties, the impact and fatigue strength of PMMA are not entirely satisfactory, thus may fail when there is excessive parafunctional or functional forces .The hybrid denture got its strength from the metal framework thus reduces the chances of fracture.

Producing a passive-fitting substructure for fixed removable screw retained hybrid prosthesis is arguably one of the most technically complex tasks in implant dentistry. In spite of a number of techniques to prevent or correct distortions that occur during impression making, cast pouring, waxing, casting, indexing, and soldering, errors in the fit of frameworks persist. ${ }^{[9]} \mathrm{A} 50 \mu \mathrm{m}$ misfit may require the implant to move within the bone $200 \mu \mathrm{m}$ before the casting fits passively. ${ }^{[10]}$. The technique presented may not initially produce a perfectly passive framework, but adjustments to the internal surfaces of the framework improved the fit.

The rehabilitation of edentulous patients with hybrid dentures has been observed to achieve greater masticatory function and psychological satisfaction than with conventional over-dentures. ${ }^{[11]}$ Occlusal forces have been increased considerably following the placement of an implant-supported prosthesis. ${ }^{[12]}$

It should be kept in mind that passive fit is the prerequisite for survival of implants in bone (13, 14) and not achieving it leads to mechanical and biological failures $(15,16)$. Passive fit can usually be achieved through precise laboratory work and special attention during framework 
try-in. However, if the framework does not have an adequate fit despite all the precise work, the framework should be cut, joint with acrylic resin and solderedwhich imposes additional costs to both the patient and the dentist $(17,18)$.

\section{References}

[1]. Suma K, Seyed A, Kalarani M, and Mangala D. An organized start to implant-supported prosthesis Contemporary Clinical Dentistry, Jan-Mar 2013, Vol 4, Issue 1.

[2]. Ashish R, Deepak N, Padma A and Jacob M. Full mouth rehabilitation of a patient with mandibular implant screw retained fp-3 prosthesis opposing maxillary acrylic removable over-denture. Contemporary Clinical Dentistry, Apr-Jun 2013, Vol 4, Issue 2, Page no. 231-25.

[3]. George W, Douglas P and Gary W. An alternate treatment method for a fixed-detachable hybrid prosthesis: A clinical report (J Prosthet Dent 2003; 89:239-43).

[4]. Salenbauch NM, Langner J. New ways of designing superstructures for fixed implant-supported prostheses. Int J Periodontics Restorative Dent 1998;18:604-612.

[5]. Balshi TJ. Preventing and resolving complications with osseointegrated implants. Dent Clin North Am 1989;33:821-868.

[6]. Taylor TD, Agar JR. Twenty years of progress in implant prosthodontics. J Prosthet Dent 2002;88:89-95.

[7]. Simon H, Yanase RT. Terminology for implant prostheses. Int J Oral Maxillofac Implants 2003;18:539-543.

[8]. Mericske-Stern R. Treatment outcomes with implant-supported overdentures: clinicalconsiderations. J Prosthet Dent 1998;79:66-73.

[9]. Naert I, Quirynen M, van Steenberghe D, Darius P. A study of 589 consecutive implants supporting complete fixed prostheses. Part II: Prosthetic aspects. J Prosthet Dent. 1992;68:949-56.

[10]. Carl E. Misch. Dental implant prosthetics, $1^{\text {st }}$ edition, Elsevier publication.

[11]. Bauman GR, Mills M, Rapley JW, Hallmon WW. Plaque-induced inflammation around implants.Int J Oral Maxillofac Implants. 1992;7:330-7.

[12]. Haanaes HR. Implants and infections with special reference to oral bacteria. J Clin Periodontol.1990;17:516-24.

[13]. Klineberg IJ, Murray GM. Design of superstructures for osseointegrated fixtures. Swed Dent J 1985;28(suppl):63-69.

[14]. Goll GE. Production of accurately fitting full-arch implant frameworks: Part 1- Clinical procedures. J Prosthet Dent 1991;66:377384.

[15]. Kallus T, Bessing C. Loose gold screws frequently occur in full-arch fixed prostheses supported by osseointegrated implants after 5 years. Int J Oral Maxillofac Implants 1994;9:169-178.

[16]. Uludamar A, Leung T. Inaccurate fit of implant superstructures, Part II: efficacy of the Preci-disc system for the correction of errors. Int J Prosthondont 1996;9:16-20.

[17]. Carr AB, Stewart RB. Full-arch implant framework casting accuracy: preliminary in-vitro observation for in-vivo testing. J Prosthodont 1993;2:2-8.

[18]. Jemt T. Three-dimensional distortions of gold alloy castings and welded titanium frameworks. Measurements of the precision of fit between completed implant prostheses and the master cast in routine edentulous situations. J Oral Rehab. 1995;22:557-564. 